\title{
A QUESTÃO SOCIAL EM HANNAH ARENDT: apontamentos críticos
}

\author{
The social question in Hannah Arendt: \\ critical points
}

\author{
Adriano Correia \\ Doutor em Filosofia pela UNICAMP. Professor Adjunto da Universidade Federal de Goiás \\ (UFG), Goiânia, GO - Brasil, e-mail: correiaadriano@yahoo.com.br
}

\section{Resumo}

Nesse texto, examinarei brevemente o que Hannah Arendt nomeou de questão social em seu exame da modernidade política. Além das implicações da ascensão do social para a definição da fronteira entre o público e o privado, refletirei sobre as dificuldades para pensar o tema da justiça na obra arendtiana por conta do rigor com que ela separa o econômico e o político.

Palavras-chave: Questão social; Esfera pública; Esfera privada; Justiça.

\section{Abstract}

In this paper I examine shortly the social question in the Hannah Arendt's analyses of political modernity. Beyond the consequences of the rise of social to the dilution of the boundaries between public and private spheres, I reflect about the difficulties to think the justice in the arendtian work, because of her rigid separation between economic and political realms.

Keywords: Social question; Public sphere; Private sphere; Justice. 
A compreensão da modernidade foi uma das tarefas a que Hannah Arendt se propôs de modo privilegiado em toda a sua obra. Em um importante estudo sobre a obra de Hannah Arendt, Seyla Benhabib (1996) enfatiza o que nomeia como "modernismo relutante" na obra da autora. A relutância de Arendt traduz-se na ênfase dada por ela às contradições modernas, notadamente no âmbito político, em obras como As origens do totalitarismo, A condição humana, Sobre a revolução e Entre o passado e o futuro. Seu entusiasmo com o fenômeno revolucionário, e o sistema de conselhos, em particular, freqüentemente resulta obnubilado por suas análises profundas dos tempos sombrios cujo extremo é a dominação totalitária.

Nesse texto, examinarei algumas das principais objeções à compreensão arendtiana do conceito de esfera social ou sociedade para a configuração da sua relação com a era moderna. A escolha desse tema pode redundar na acentuação de um traço antimoderno no pensamento político arendtiano, que poderia ser matizado, por exemplo, por um exame meticuloso do fenômeno revolucionário, que não posso levar a cabo aqui. Recorri à expressão "modernismo relutante" justamente porque julgo que qualquer tentativa de situar Hannah Arendt em uma posição unívoca com relação à modernidade será inevitavelmente simplista.

No segundo capítulo de A condição humana, Hannah Arendt trata especificamente da distinção entre público e privado e reflete sobre os eventos que a tornaram obsoleta. Estes eventos podem ser compreendidos, em sua obra, no movimento de ascensão da esfera social e do surgimento da sociedade de massas, que, embora distintos, fazem parte do mesmo processo de expansão (e simultânea diluição) da privatividade, de elevação da satisfação das necessidades vitais (a dependência mútua em prol da subsistência) a aspecto vinculante fundamental da política, de promoção da uniformidade e da decorrente identificação entre ação e comportamento.

O que marca a consolidação do mundo moderno, na avaliação de Arendt, é uma progressiva indistinção entre as esferas social e política, com a conseqüiente "ascensão do 'lar' (oikia) ou das atividades econômicas ao domínio público" (ARENDT, 1958, p. 33). A esfera social é "o domínio curiosamente híbrido onde os interesses privados adquirem significação pública" (ARENDT, 1958, p. 35). O que caracteriza a modernidade política é a compreensão da política como uma função da sociedade, com a implicação fundamental de que as questões eminentemente privadas da sobrevivência e da aquisição transformaram-se em interesse coletivo, ainda que nunca se possa conceber de fato de tal interesse como sendo público.

A voracidade da esfera social por expansão acaba por confinar a esfera privada à intimidade e restringir as possibilidades da ação na esfera pública 
em vista da estabilidade necessária à preservação da vida e dos processos de acumulação - "a sociedade, quanto ingressou pela primeira vez na esfera pública, assumiu o disfarce de uma organização de proprietários que, em vez de solicitar o acesso à esfera pública por sua riqueza, exigiam dela proteção para a acumulação de mais riqueza" (ARENDT, 1958, p. 68). A ascensão do social fez com que o conformismo, como garantia de estabilidade, se tornasse uma ameaça permanente. Efetivamente, "a sociedade é a forma na qual o fato da dependência mútua em prol da vida e de nada mais assume um significado público, e onde é concedida às atividades vinculadas com a mera subsistência a aparição em público" (ARENDT, 1958, p. 46). Não obstante, a publicação do íntimo não o torna público, nem remedia a perda de grandeza, da possibilidade de desfrutar daquilo que ao menos desde o século XVIII se chamava de felicidade pública, a compensar o necessário sacrifício dos interesses individuais em vista do bem comum. Com efeito, diz Arendt, "realmente a liberdade, a vida política, a vida do cidadão - esta 'felicidade pública' de que falei - é um luxo; uma felicidade adicional para a qual se torna apto apenas depois de as solicitações do processo vital terem sido satisfeitas" (ARENDT, 1977, p. 106).

Para compreender a relação entre a ascensão da esfera social e a progressiva transformação e declínio da esfera pública como fenômeno político, importa evidenciar a intrínseca relação entre esta esfera social e as modernas sociedades de massas. Em primeiro lugar, ao contrário do que se daria no interior de qualquer esfera política, a sociedade espera de cada um de seus membros, em vez de ação, certo tipo de comportamento comum - e talvez a diferença política mais relevante entre agir e se comportar seja o caráter previsível e manipulável do comportamento, em oposição ao caráter espontâneo e fugidio da ação. O caráter monolítico de todo tipo de sociedade certamente se assenta, para Hannah Arendt, no fato de que nela os homens estão unidos simplesmente enquanto membros da humanidade, enquanto naturalmente sujeitos às mesmas necessidades. É nesse sentido que a expansão da esfera social sobre as esferas privada e pública tem como decorrência a canalização do próprio processo da vida para a esfera pública ou, mais precisamente, a diluição da fronteira que mantinha o público e o privado como esferas distintas. A hipótese central de Arendt a esse respeito, como indica M. P. D’Entrevés, é que:

A destruição da fronteira que separa o privado do público reduziu a política a um assunto de economia doméstica nacional, isto é, a uma atividade não mais caracterizada por ação, liberdade, participação e deliberação, mas por trabalho, necessidade, governo e administração burocrática. (D’ENTREVÉS, 1994, p. 59). 
Para Hannah Arendt, na medida em que a sociedade de massas indica basicamente a absorção dos diversos grupos sociais por uma sociedade única, o seu surgimento é a expressão de que "a esfera do social, finalmente, após vários séculos de desenvolvimento, alcançou o ponto onde ela abrange e controla todos os membros de uma dada comunidade, igualmente e com igual força" (ARENDT, 1958, p. 41). As atividades econômicas se expandiram a ponto de adquirirem um conteúdo político, fazendo com que a vida política seja compreendida segundo o modelo de uma grande família a zelar pelas necessidades vitais de todos. Para ela, a questão é que:

Onde a vida está em jogo, toda ação está, por definição, sob o domínio da necessidade, e o âmbito próprio para cuidar das necessidades vitais é a gigantesca e ainda crescente esfera da vida social e econômica, cuja administração tem ofuscado o âmbito político desde o início da época moderna. (ARENDT, 1993, p. 155).

O conceito de esfera social defendido por Hannah Arendt, certamente fundamental a toda a sua crítica à forma como se desenvolveu a política moderna, não tem deixado de ser alvo de variadas e severas críticas, freqüentemente elaboradas por estudiosos da sua obra, mesmo aqueles inspirados por ela. Para J. Habermas, na medida em que ela estiliza a imagem da pólis, e adota, em decorrência, as suas rígidas distinções, é natural que admita como sintoma patológico - da confusão entre o político e o social - a nova relação complementar entre o Estado e a economia. Para ele, não é caminho viável para nenhuma sociedade moderna a perspectiva sui generis adotada por Hannah Arendt:

Um Estado, exonerado da elaboração administrativa de matérias sociais; uma política, depurada das questões relativas à política social; uma institucionalização da liberdade pública, que independe da organização do bem-estar; um processo radical de formação democrática da vontade, que se abstém em face da repressão social. (HABERMAS, 1980, p. 110). ${ }^{1}$

O problema, ainda de acordo com Habermas, é que as teses arendtianas são decorrência mais de uma construção filosófica que de "pesquisas equilibradas", de modo que enquanto ela permanecer sob a influência de uma

Para uma análise crítica da crítica de Jürgen Habermas a Hannah Arendt ver MAGALHÃES, T. C. de. Ação e poder em Hannah Arendt e J. Habermas. Salvador: Quarteto, 1980. p. 185200. e também FERRY, Jean-Marc. Habermas critique de Hannah Arendt. Esprit, n. 6, p. 109-124. Jun. 1980. 
teoria da ação vinculada a Aristóteles, seu conceito de poder "comunicativamente produzido", por exemplo, e a sua concepção política como um todo, não conseguirão escapar de contra-sensos quando aplicados às sociedades modernas nem se converter em um instrumento válido. O equívoco, por fim, para ele, consiste em identificar a política "à práxis daqueles que conversam entre si, a fim de agirem em comum" (HABERMAS, 1980, p. 115). Em todo caso, a despeito de suas agudas observações, Habermas seguramente se equivoca quando filia Arendt à tradição contratualista e também quando passa ao largo do vigor crítico das rígidas distinções na obra de Arendt.

Em semelhante direção de crítica, mas com uma preocupação específica com a caracterização arendtiana da esfera social, e o modo como se estabelece, a partir dela, a relação entre economia e política, temos as análises críticas de M. P. D’Entrevés, H. Pitkin, C. Pateman, N. Fraser, S. Benhabib, dentre outros. M. P. D'Entrevés dirige duas críticas principais: em primeiro lugar, a caracterização arendtiana da esfera social - como sendo a esfera do trabalho, das necessidades biológicas e materiais, da reprodução das nossas condições de existência - parece muito restrita. Para ele, muito embora esta caracterização possa ser adequada às atividades realizadas na esfera que ela define como privada, "é totalmente imprópria como uma descrição das modernas formas industriais de produção, com suas altas taxas de acumulação de capital e seu alto nível de crescimento econômico" (D’ENTREVÉS, 1994, p. 60). Desse modo, identificando o social com as atividades econômicas de reprodução simples, Hannah Arendt, segundo ele, corre o risco de negligenciar o fato de que as economias capitalistas modernas geram um excedente que vai muito além das necessidades de reprodução.

Em segundo lugar, D'Entrevés considera que, sustentada em tal análise, Hannah Arendt torna-se "incapaz de reconhecer que uma economia capitalista moderna constitui uma estrutura de poder, determina a alocação de recursos e a distribuição de responsabilidades e recompensas" (D'ENTREVÉS, 1994, p. 60-61). ${ }^{2}$ De maneira geral, enfim, ele defende que por se basear na

2 Na mesma direção ver WOLIN, Sheldon . Hannah Arendt: democracy and the political. Salmagundi, Londres, n. 60, p. 9-10, 1983, argumenta que Arendt "nunca conseguiu compreender a lição básica ensinada não apenas por Marx, mas também pelos economistas clássicos, de que uma economia não é meramente trabalho, propriedade, produtividade e consumo: é uma estrutura de poder, um sistema de relações contínuas em que o poder e a dependência tendem a tornar-se cumulativos e as desigualdades são reproduzidas em formas cada vez mais sofisticadas". 
"enganosa analogia" com a família, Hannah Arendt incorre no duplo equívoco de manter as questões referentes à economia em um âmbito pré-político e ignorar a relação crucial entre poder econômico e exploração.

Seyla Benhabib, por seu turno, articula suas críticas à metodologia, à distinção público/privado e à esfera social em Hannah Arendt num mesmo grupo. A metodologia adotada por Arendt na compreensão da política estaria envolvida por uma dupla tensão. A primeira se refere ao fato de que seu pensamento não estaria livre da suposição - derivada da Ursprungsphilosophie (uma filosofia da origem ou do sentido originário) - que localiza um estado original ou um ponto temporal como privilegiado para a busca por capturar o sentido verdadeiro dos fenômenos. Para Benhabib, esta concepção seria inspirada pela fenomenologia de Husserl e Heidegger, segundo a qual "a memória é a recordação mimética das origens perdidas dos fenômenos enquanto contidas em alguma experiência humana fundamental" (BENHABIB, 1996, p. 77).

A segunda tensão refere-se à concepção arendtiana do pensamento político como storytelling, tentando pensá-lo por meio da história humana, sedimentada nas camadas da linguagem (uma Begriffsgeschichte). Para Benhabib, a decorrência metodológica deste comprometimento teórico, acerca do conceito de política é a construção de um método historiográfico fragmentário - que busca, não obstante, vale dizer, restabelecer a possibilidade de articulações significativas entre os fenômenos -, inspirado por Benjamin, e que consiste em "uma lembrança, no sentido de um ato criativo de 'remembrar' (re-membering), isto é, de colocar juntos os membros de um todo, de um repensar que libera as perdas potenciais do passado" (BENHABIB, 1996, p. 76). Hannah Arendt, em todo caso, afirma ser parte de seu pressuposto, e não de seu método, uma desconstrução da metafísica que tem por assentada tanto a ruptura quanto a impossibilidade de reatamento do fio da tradição.

Seria a denúncia arendtiana da relação entre ascensão da esfera social e o declínio do espaço público uma decorrência dessa dupla tensão metodológica. Para Benhabib, enquanto Hannah Arendt lamenta a diluição das fronteiras entre o público e o privado por meio da ascensão do social, a emancipação dos trabalhadores torna as relações de propriedade uma questão de política pública; a emancipação da mulher torna a família e a esfera privada questões públicas; a conquista de direitos por pessoas não-brancas e não-cristãs tem colocado as questões culturais de identidade coletiva e outras representações na agenda pública. Em Benhabib, estas e outras disputas sobre o que deve ser incluído na agenda pública são, simultaneamente, lutas por justiça e liberdade. Por isto defende que: 
A distinção entre o social e o político não faz sentido no mundo moderno, não porque toda a política se tornou administração e porque a economia se tornou a quintessência pública, como pensa Hannah Arendt, mas principalmente porque a disputa para tornar pública alguma coisa é uma luta por justiça. (BENHABIB, 1996, p. 79).

Hanna Pitkin (1991) já havia apontado pioneiramente a ausência da questão da justiça na obra arendtiana. Isto se daria não porque Hannah Arendt considerasse esta questão sem importância, mas porque estava determinada a isolar a esfera pública de qualquer questão pertencente ao domínio do social, no intuito de preservá-la da destruição. Por insistir em uma rígida separação entre o social e o político, ela teria se tornado incapaz de preservar para a justiça o lugar central que deveria ocupar em toda teoria política. Mais que isso, ela acabaria por ter de tratar o social e o econômico como questões técnicas que requerem soluções administrativas (D’ENTREVÉS, 1994, p. 61).

Isso seria decorrência - na análise de Benhabib - de um "essencialismo fenomenológico" de Hannah Arendt, por meio do qual o espaço público seria definido como lugar somente de certo tipo de atividade: a ação, oposta à fabricação e ao trabalho, e delimitada "por referência ao conteúdo substantivo do diálogo público". Desse modo, Hannah Arendt relegaria:

Certos tipos de atividades como fabricação e trabalho [que para Benhabib também são tipos de ação] e, por extensão, todas as questões de economia e tecnologia, somente à esfera privada, ignorando o fato de que estas atividades e relações também, na medida em que são baseadas em relações de poder, poderiam tornar-se assunto de disputa pública. (BENHABIB, 1996, p. 80).

De uma maneira mais geral, Benhabib se pergunta:

Se o espaço agonístico da pólis era possível somente porque grandes grupos de seres humanos - como mulheres, escravos, crianças, trabalhadores, não cidadãos residentes, e todos os não-gregos estavam excluídos dele, ao mesmo tempo em que tornavam possível, por meio do seu trabalho para as necessidades da vida cotidiana, aquele 'tempo livre para a política' que era desfrutado por poucos, então a crítica da ascensão do social, que foi acompanhada pela emancipação desses grupos do 'sombrio interior do lar' e por sua entrada na vida pública, é também uma crítica ao universalismo político como tal? (BENHABIB, 1996, p. 75). 
Isto é o mesmo que perguntar se a redescoberta do mundo público na época moderna só seria possível sob uma perspectiva elitista e antidemocrática, dificilmente reconciliável com a busca pela emancipação universal e pela extensão dos direitos do cidadão, que acompanham a modernidade ao menos desde as revoluções Francesa e Americana. Ou seja, se é possível pensar a política na modernidade, sem abrir mão do que talvez seja a sua maior conquista política, a inclusão ideal de todos os indivíduos e grupos sociais no interior do espaço público.

O problema, para Benhabib, é viabilizar uma concepção de espaço público que abranja, pela discursividade, e não por um "essencialismo fenomenológico", desde a definição da agenda de conversação pública até uma ampla discussão, envolvendo os mais diversos grupos sociais, no que se refere à deliberação acerca dos temas tidos como públicos, sejam eles oriundos do âmbito "privado", "social" ou "público". Para ela, Hannah Arendt desenvolve, com seu modelo associativo, não um conceito substantivo, mas procedimental de espaço público, no qual o que realmente importa não é o que tem lugar no discurso público, mas o modo como este discurso se dá. Isto é, se desse discurso está excluído todo elemento de força e violência - que insere a superioridade física no âmbito da linguagem - em nome da predominância da persuasão e da convicção. É nesse sentido que, para ela, do ponto de vista deste modelo procedimental arendtiano de esfera pública, "nem a distinção entre o social e o político nem a distinção entre obra, trabalho e ação são relevantes" (BENHABIB, 1996, p. 81).

A questão é que a política moderna formou para si, desde o início, um novo conceito de participação. A emergência de uma esfera pública autônoma de raciocínio público e discussão é central a este projeto de participação. Para Benhabib, é possível, senão necessário, conciliar participação e democracia moderna, embora não recorrendo aos pensadores da tradição das virtudes cívicas ou inspirados pelo modelo de cidadania da pólis - que não poderiam fornecer uma resposta ao problema da participação para as complexas sociedades modernas, com suas esferas altamente diferenciadas da economia, da lei, política, civil e da vida familiar - mas ao que ela chama, pensando principalmente na obra de Jürgen Habermas, de teoria crítica contemporânea. Esta teoria seria a mais capaz de fornecer uma formulação aceitável e contextualizada do conceito de participação, incluindo tanto o conceito de "formação discursiva da vontade" quanto a expansão da participação da esfera política para contemplar também às esferas cultural e social. (BENHABIB, 1996, p. 85-86). 
Por estas razões, o modelo arendtiano de espaço público estaria em desvantagem em relação ao modelo liberal - concebido como diálogo público - e ao modelo discursivo habermasiano. Em primeiro lugar, se comparado com o modelo liberal, o arendtiano tem muito mais dificuldade, na visão de Benhabib, em estabelecer um vínculo claro e substantivo entre poder, legitimidade e discurso público. A vantagem do modelo habermasiano sobre ambos se assenta no fato de que o seu modelo discursivo de espaço público "é radicalmente indeterminado e aberto". Ele não estabelece de antemão, por exemplo, a agenda do debate público, nem restringe o acesso ao espaço onde se dá esse debate. Desse modo, "o modelo discursivo é o único que é compatível tanto com a tendência social geral de nossas sociedades e com as aspirações emancipatórias dos novos movimentos sociais, como o movimento das mulheres" (BENHABIB, 1996, p. 84-95), na medida em que permite o surgimento de um espaço e um discurso públicos nos quais se daria uma democratização das questões tornadas públicas, de modo que estas pudessem ser envolvidas no debate, na reflexão, na ação e transformação político-moral envolvidas no processo de formação discursiva da vontade. Em suma, segundo este modelo crítico de espaço público e discurso público, compartilhado, segundo Benhabib, por Habermas e pelo movimento feminista:

O espaço público não é entendido agonisticamente como um espaço de competição por aclamação e imortalidade entre uma elite política; ele é visto democraticamente como a criação de procedimentos pelos quais esses afetados pelas normas sociais gerais e pelas decisões políticas coletivas possam opinar em sua formulação, estipulação e adoção. (BENHABIB, 1996, p. 87).

Benhabib força sua interpretação, segundo julgo, quando afirma que Arendt, em decorrência do seu "essencialismo fenomenológico", insiste em separar ação de fabricação e trabalho, fazendo simultaneamente com que questões de economia e política, relegadas à esfera privada, mas baseadas em relações de poder, pudessem vir a tornar-se assunto de disputa pública. $\mathrm{O}$ problema não está necessariamente na expressão "essencialismo fenomenológico" e na sua conotação pejorativa, mas na defesa de que as relações sobre as quais se assentam o trabalho e a fabricação, a economia e a tecnologia, são relações de poder, mesmo quando não tomamos este último termo no sentido atribuído a ele por Hannah Arendt. As relações que aí se dão, quando ultrapassam o âmbito meramente econômico, raramente chegam a ser mais do que, voltando à terminologia arendtiana, relações de domínio. 
Hannah Arendt reconhece que em cada uma das questões sociais "há uma dupla face" (ARENDT, 1979, p. 318). O que ela não deixa claro, e que demandaria um exame mais detido que o que posso levar a cabo aqui, é o mecanismo ou o procedimento por meio do qual as questões sociais, que possuem relevância para a coletividade e cuja solução é pressuposta no pleno exercício da cidadania, sejam admitidas no domínio político sem provocar a sua ruína ou se converter em uma usurpação do espaço público por interesses privados - enfim, como conciliar espaço político e justiça.

Quando pergunta se a crítica da ascensão do social equivale a uma crítica do universalismo como tal, Benhabib tende a responder afirmativamente. Se o fizesse, desconsideraria a preocupação de Hannah Arendt com uma ampla participação política. A questão é que a participação social, tal como parece defender Benhabib, é para Arendt justamente o tipo suposto por uma democracia eleitoral que camufla a ausência efetiva do conjunto da população da participação efetiva no domínio público sob a defesa pública dos interesses de indivíduos ou grupos. Além disso, esta ilusão do democratismo moderno da participação da maioria absoluta da população no exercício do poder é o tipo de suposição que o totalitarismo fará ruir, na medida em que mobilizou e se sustentou constantemente nessa massa apolítica, tanto nos seus brados quanto no seu consentimento silencioso. Em suma, emancipação social não é equivalente a universalismo político, ao mesmo tempo em que não podemos considerar, a priori, a inclusão ideal de todos os indivíduos e grupos sociais no interior do espaço público uma conquista política completa. Hannah Arendt parece mais exigente: "ou liberdade política significa, de um modo geral, o direito de 'ser um participante no governo' ou não significa coisa alguma” (ARENDT, 1973, p. 218). Se não podemos organizar tal tipo de participação, nem recorrer a um modelo de representação que o incorpore, não conseguiremos constituir um espaço político.

Uma rígida separação entre os espaços público e privado, entre esferas de igualdade e desigualdade legítimas, impediria o tratamento público de questões privadas, por assim dizer, mas publicamente relevantes, dentre as quais podemos indicar a violência doméstica, aberrantes desigualdades sociais, etc. Afinal, para Seyla Benhabib, a face agonística do conceito arendtiano de esfera pública o tornaria incongruente com a realidade sociológica da modernidade assim como com as modernas disputas políticas por justiça (embora a mesma S. Benhabib sublinhe que o modelo associativo de espaço público em Hannah Arendt é muito relevante para pensar a 
experiência da política em todos os novos movimentos sociais) (BENHABIB, 1996, p. 95, nota 36).

O conceito arendtiano de esfera pública reserva um potencial emancipatório significativo, aliado a uma valorização da dignidade da política, quando insiste que emancipação social não equivale à emancipação política. A despeito das dificuldades para pensar a nossa época, decorrentes do rigor com que Hannah Arendt exclui tudo o que é da ordem do econômico do domínio público, foi a própria Arendt quem assinalou, de um lado, que todos os seres humanos são capazes de ação e cidadania e, por outro, quem reconhecia que na pólis "o preço da eliminação do fardo da vida dos ombros de todos os cidadãos era enorme e de modo algum consistiu apenas na injustiça violenta de forçar uma parte da humanidade a ingressar na treva da dor e da necessidade" (ARENDT, 1958, p. 119).

Para encerrar, menciono um trecho publicado postumamente em que ela debate um texto intitulado "Direitos privados e o bem público" com uma réplica intitulada "Direitos públicos e interesses privados". Tal trecho indica, no tom coloquial do debate, o quanto Hannah Arendt estava consciente do que está em questão aqui:

O que dizer dos direitos privados de indivíduos que são também cidadãos? [Como os interesses e direitos privados de alguém podem ser reconciliados com o que se tem direito a exigir dele enquanto um cidadão?] [...] realmente a liberdade, a vida política, a vida do cidadão - esta "felicidade pública" de que falei - é um luxo; uma felicidade adicional para a qual se torna apto apenas depois de as solicitações do processo vital terem sido satisfeitas. Desse modo, se falamos de igualdade, a questão é sempre a seguinte: quanto temos de transformar as vidas privadas dos pobres? Em outras palavras, quanto dinheiro temos de dar a eles para torná-los aptos a desfrutar da felicidade pública? Educação é muito bom, mas o que importa mesmo é dinheiro. Somente quando puderem desfrutar do público é que estarão dispostos e aptos a fazer sacrifícios pelo bem público. Requerer sacrifícios de indivíduos que ainda não são cidadãos é exigir deles um idealismo que eles não têm e nem podem ter em vista da urgência do processo vital. Antes de exigirmos idealismo dos pobres, devemos antes tornálos cidadãos: e isto implica transformar as circunstâncias de suas vidas privadas de modo que se tornem aptos a desfrutar do 'público'. (ARENDT, 1977, p. 106-107). 


\section{Referências}

ARENDT, H. The human condition. Chicago: Un. Chicago Press, 1958.

On revolution. Harmondsworth, Middlesex: Penguin Books, 1973.

Public rights and private interests. In: MONEY; STUBER (Org.).

Small comforts for hard times: Humanists on public policy. New York: Columbia University Press, 1977.

On Hannah Arendt. In: HILL, M. A. Hannah Arendt: the recovery of the public world. New York: St. Martin's Press, 1979.

What is freedom? In:

Between past and future. New York:

Penguin Books, 1993.

BENHABIB, S. Models of public space: Hannah Arendt, the Liberal tradition, and Jürgen Habermas. In: CALHOUN, C. (Ed.). Habermas and the public sphere. 4. ed. Massachusetts: The MIT Press, 1996. p. 73-98.

D'ENTREVÉS, M. P. The political philosophy of Hannah Arendt. London; New York: Routledge, 1994.

FERRY, Jean-Marc. Habermas critique de Hannah Arendt. Esprit, Paris, n. 6, p. 109-124, Jun. 1980.

HABERMAS, J. O conceito de poder em Hannah Arendt. In: FREITAG, B.; ROUANET, S. P. (Org.). Habermas. São Paulo: Ática, 1980.

MAGALHÃES, T. C. de. Ação e poder em Hannah Arendt e J. Habermas. Salvador: Quarteto, 1980. p. 185-200.

PITKIN, H. F. Justice: on relating private and public. Political Theory, Berkeley, v. 9, n. 3, p. 327-352, 1991.

WOLIN, S. H. Arendt: democracy and the political. Salmagundi, Londres, n. $60,1983$. 